\title{
Studies on microwave assisted hot air drying characteristics and rehydration of Bitter gourd (Momordica charantia $\mathbf{L}$.)
}

\author{
Sarvesh Kumar, Krishan Kumar and Chandra Prakash \\ Baba Farid Institute of Technology, Deharadun
}

\begin{abstract}
Fresh bitter gourd was procured from the local market were subjected to microwave and microwave assisted hot air drying. During microwave drying, power levels were kept as 160, 320 and 480W. Samples were dried in hot air dryer at $60^{\circ} \mathrm{C}$ and $1 \mathrm{~m} / \mathrm{s}$ air velocity. The drying time ranged between 25 to 40 minutes for all power levels. The drying time for unblanched sample was $25 \%$ less than the blanched sample. Drying rate of bitter gourd increased with increase in power from $160 \mathrm{~W}$ to $480 \mathrm{~W}$. In hot air drying of bitter gourd drying was faster for the blanched samples. In microwave assisted hot air drying, a sudden increase in drying rate was observed when samples partially dried in hot air dryer were subjected to microwave drying. The microwave dried bitter gourd slices exhibit lower rehydration capacity than the other two drying methods because of case hardening which does not allow further absorption of moisture from the sample. Of all the experimental drying methods, the rehydration capacity of the sample dried in microwave assisted hot air drying method had the highest value. The rehydration capacity was more for blanched sample (666.67\%) as compared to unblanched sample $(352.27 \%)$ during microwave assisted hot air drying at $160 \mathrm{~W}$.
\end{abstract}

Key words: Bitter gourd, Hot-air drying, Microwave drying, Rehydration.

Paper Cited: Kumar, S., Kumar, K. and Prakash, C. (2015). Studies on microwave assisted hot air drying characteristics and rehydration of Bitter gourd. South Asian J. Food Technol. Environ. 1(2):144-151.

Vegetables are an important part of human diet. They provide proteins, carbohydrates, mineral elements, vitamins and bulk which along with some cereals and other foods, constitute the essentials of a balanced diet. India ranks first in the production of fruits in the world; also is the second largest producer of vegetables (next to China) and accounts for about $15 \%$ of the world's production of vegetables.

Bitter gourd belongs to 'Cucurbitaceae' family and its scientific name is Momordica charantia L. All the parts of the plant, including the fruit, taste very bitter. The presence of momordicines in bitter gourd is responsible for its bitter taste. The popular indigenous varieties of bitter gourd may be classified as green and white, the latter is considered tastier. The bitter gourd is reported to be originated in the tropics of world that is widely distributed in China, Malaysia, India and tropical Africa. Bitter gourd also grows in parts of the Amazon, East Africa, Gulf coast of United States and the Caribbean and is cultivated throughout South America as a food and medicine. (Anon, 2010).

Bitter gourd contains an array of biologically active plant chemicals including triterpenes, proteins and steroids. Bitter gourds have extremely low amount of calories but have a lot of valuable nutrients. It is a rich resource for vitamins B1, B2 and B3, C, folic acid, magnesium, phosphorus, zinc and manganese and includes high nutritional fiber. It consists of about $88.42 \%$ water, $3.2 \%$ protein content, $5.62 \%$ total ash content and ascorbic acid is $11.1 \mathrm{~g} / 100 \mathrm{~g}$. The quantity of reducing sugar, non reducing sugar and total sugar is $3.45 \%, 0.3 \%$ and $3.75 \%$ respectively (Kulkarni et al., 2005).

Bitter gourd stimulates easy digestion and peristalsis of food through the bowel until it is excreted from the body. Thus, helps in relieving indigestion and constipation problems. The fruit is considered as tonic, stomachic, carminative and cooling and is used in the treatment of rheumatic, gout and other diseases of liver and spleen. The aqueous extract of bitter gourd contains a hypoglycemic compound which has clinical application to control diabetes. Fresh bitter gourd is an excellent source of vitamin-C which helps body to scavenge deleterious free radicals responsible for cancers development.

Drying makes foods more concentrated in form than foods preserved in other ways. They are less costly to produce, store and transport than canned or preserved foods. However, blanching of vegetables prior to drying is required to protect their colour, texture and nutrients and to inactivate harmful enzymes. Blanching has several advantages as it reduces drying time; inactivates the enzyme that brings undesirable changes in food product, expulses air from the tissue and better retains minerals and acids.

Present investigation was undertaken with the objectives to determine the drying characteristics of bitter gourd by hot air drying, microwave drying and microwave assisted hot air drying and determination of rehydration characteristics of dried bitter gourd using different drying methods.

\section{Materials and Methods}

Good quality fresh and tender raw bitter gourd of uniform medium size and dark green color, free from infestation, blemishes, dirt or mud 
were procured from market. Fruits were washed and cut into the slices of thickness $5 \pm 0.1 \mathrm{~mm}$.

Blanching of the bitter gourd slices was carried out in boiling water. About $200 \mathrm{~g}$ of the sample was kept in one litre of boiling water for 3 minutes. Moisture content of the bitter gourd slices was determined as outlined in AOAC (1995).

Sample slices in triplicate were kept in a microwave oven for drying. Drying was carried out at $100 \%$ microwave level for different powers. It was observed that burning and charring occurred at powers greater that $480 \mathrm{~W}$. Hence, for drying of the bitter gourd sample three microwave powers were selected viz. 160, 320 and $480 \mathrm{~W}$. The samples were taken out and weighed after an interval of 5 minutes. The drying was continued till no change in the weights of the sample was observed.

Hot air drying was conducted at the constant air velocity of $1 \mathrm{~m} / \mathrm{s}$ and constant temperature of $60^{\circ} \mathrm{C}$. The critical point i.e. the point where the first falling rate reduces to the second falling rate was observed when the samples were dried in hot air dryer only. The critical point was observed from the drying rate ( $\mathrm{g}$ water/ g dry solids/ min) v/s time (min) curve plotted for hot air drying. Microwave drying was carried out for the second falling rate. Observations were taken after regular intervals and the drying was continued until no weight change.

Fick's model was used to determine moisture ratio (Maskan, 2001). The equilibrium moisture content was determined using following expression as described by (Handerson and Perry, 1976). The rehydration capacity, described as percentage water gain, was calculated from the sample weight difference before and after the rehydration (Maskan, 2001).

\section{Results and Discussion}

Bitter gourd slices were dried using different methods of drying viz. microwave drying, hot air drying and microwave assisted hot air drying. In the later case, the drying parameters such as blanching (treatment of bitter gourd in boiling water for 3 minutes), microwave powers were optimized on the basis of least drying time and maximum rehydration ratio.

Drying rate showed a fast increase at the beginning of the process and a subsequent decrease afterwards showing two differentiated periods i.e. the first, where drying rate decreases slowly to reach a plateau with a practically constant value; and the second with a rapidly decreasing drying rate.

\section{Microwave drying}

In microwave drying, the drying time decreased with increase in power level from $160 \mathrm{~W}$ to $480 \mathrm{~W}$ of microwave drying. The drying time ranged between 25 to 40 minutes for all power levels (Fig. 1, 2 and 3). By increasing the power from $160 \mathrm{~W}$ to $480 \mathrm{~W}$ the drying time decreased by
$37.5 \%$. It was observed that at $160 \mathrm{~W}$ power of microwave, the drying time for unblanched sample was $25 \%$ less than the blanched sample. The drying time for both the samples were almost equal at 320 $\mathrm{W}$, but as the power was increased to $480 \mathrm{~W}$, blanched samples showed lesser drying time than unblanched samples.

Drying rate of bitter gourd increased with increase in power from $160 \mathrm{~W}$ to $480 \mathrm{~W}$ and after some time drying rate decreased with increase in power for blanched as well as unblanched samples (Fig. 8 and 9). This is because, at higher powers due to high initial drying rate very little moisture is left in sample and thus drying rate decreased rapidly. Similar results were obtained by Kaur and Singh, (2014) during hot-air drying followed by microwave finish drying of beetroot slices and Workneh and Oke, (2012) during combined microwave and hot-air drying of tomato slices.

\section{Microwave Assisted Hot Air Drying}

In microwave assisted hot air drying, a sudden increase in drying rate was observed when samples partially dried in hot air dryer were subjected to microwave drying. This is because of the fact that drying rate is much higher in microwave. Hence, drying rate increased when samples were first dried in hot air drying and then at the point of inflection, were subjected to microwave drying (Fig. 10 and 11). Drying rate was more for unblanched samples as compared to blanched samples. While, time taken for powers 160 and $320 \mathrm{~W}$ were same but samples dried in 480 $\mathrm{W}$ power had lesser moisture content. Drying time was reduced by about $6.7 \%$ as microwave power was increased to $480 \mathrm{~W}$ (Fig. 5, 6 and 7).

Drying rate of bitter gourd was increased after inflection point (during microwave drying) with increase in power level from $160 \mathrm{~W}$ to $480 \mathrm{~W}$ for blanched and unblanched samples. Although bitter gourd has high moisture content, a constant rate period was not observed for all experimental drying methods. The reason for the existence of two falling rate periods may be case hardening which acts as a barrier to moisture migration during prolonged drying. The case hardening is due to migration of soluble solids to the surface of the sample due to high surface temperature and building up of such soluble materials at the surface as the as the water evaporates. The pattern for drying rate curve observed in this study for bitter gourd was similar to that reported for bananas (Maskan, 2000) and kiwifruit (Maskan, 2001).

\section{Rehydration Capacity}

During reconstitution of dehydrated products the amount and rate of water absorption determines to a considerable extent the sensorial properties. The microwave dried bitter gourd slices exhibit lower rehydration capacity than the other two drying methods. The reason behind this is case 


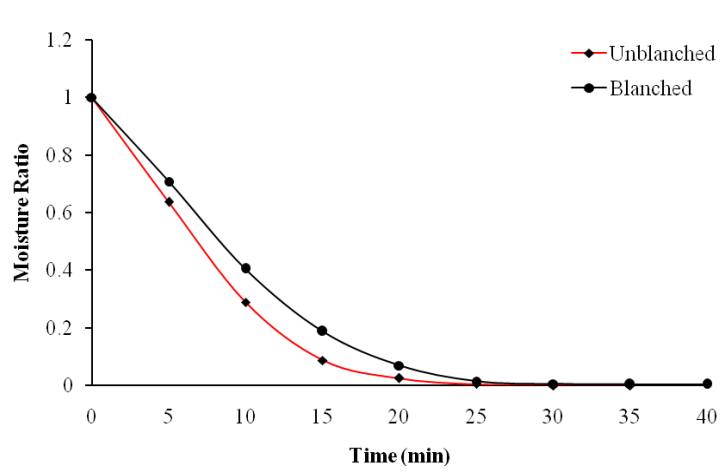

(a) Moisture ratio v/s Time curve

\section{Fig.1: Microwave drying of bitter gourd slices at $160 \mathrm{~W}$}

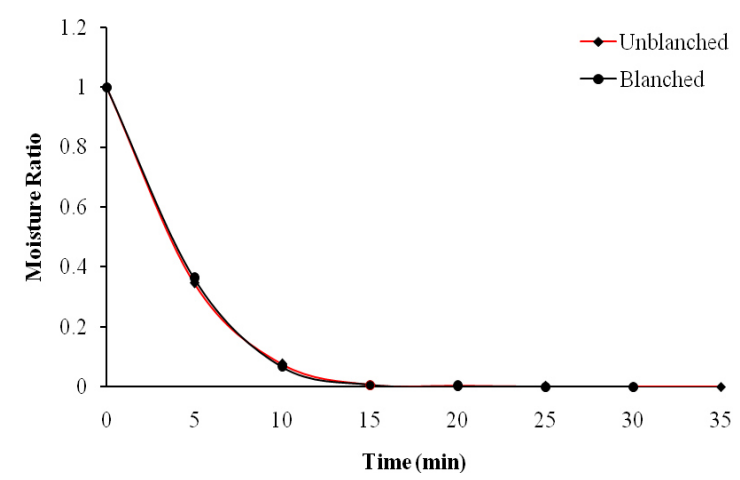

(a) Moisture Ratio v/s Time curve

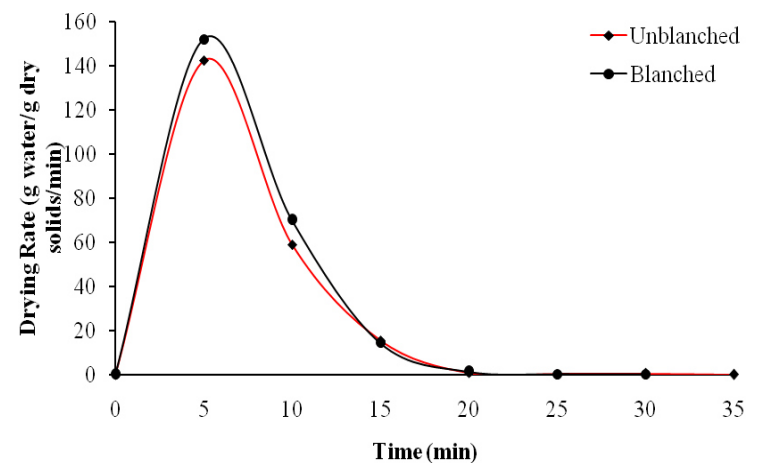

(b) Drying Rate v/s Time curve

Fig. 2: Microwave drying of bitter gourd slices at $320 \mathrm{~W}$

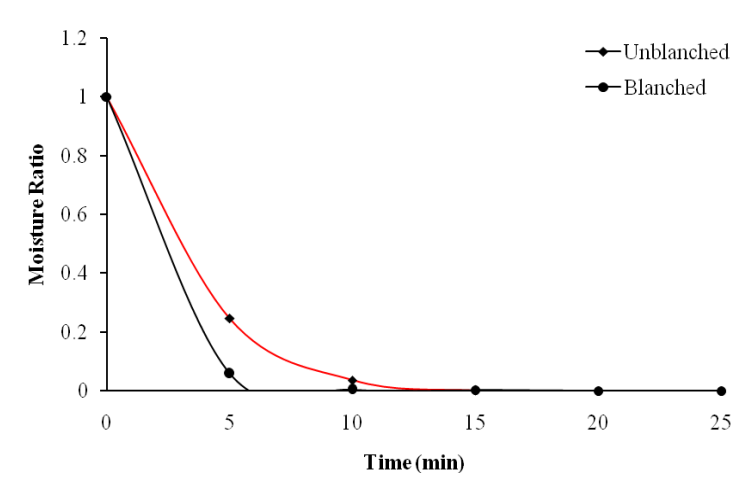

(a) Moisture ratio v/s Time curve

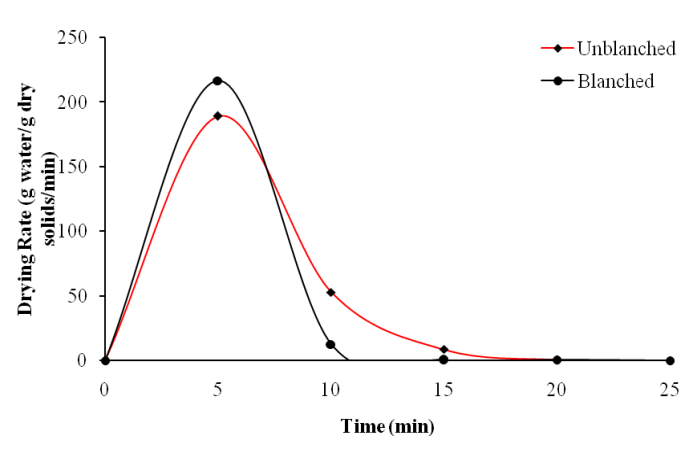

(b) Drying Rate v/s Time curve

Fig. 3: Microwave drying of bitter gourd slices at $480 \mathrm{~W}$ 


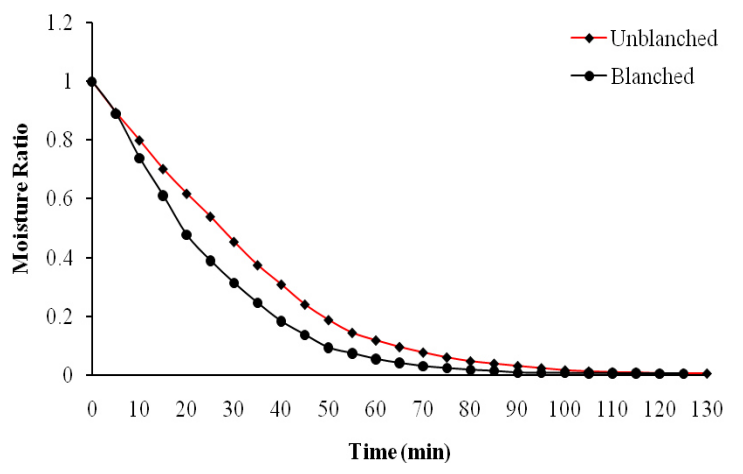

(a) Moisture ratio v/s Time curve

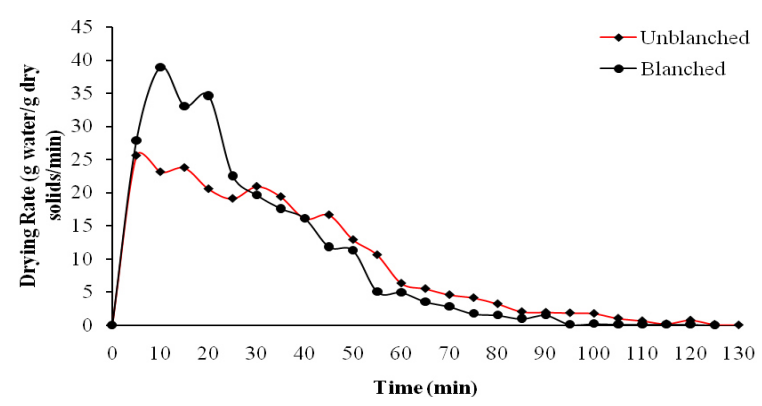

(b) Drying Rate v/s Time curve

Fig. 4: Hot air drying of bitter gourd slices at constant temperature of $60^{\circ} \mathrm{C}$ and air velocity of $1 \mathrm{~m} / \mathrm{s}$

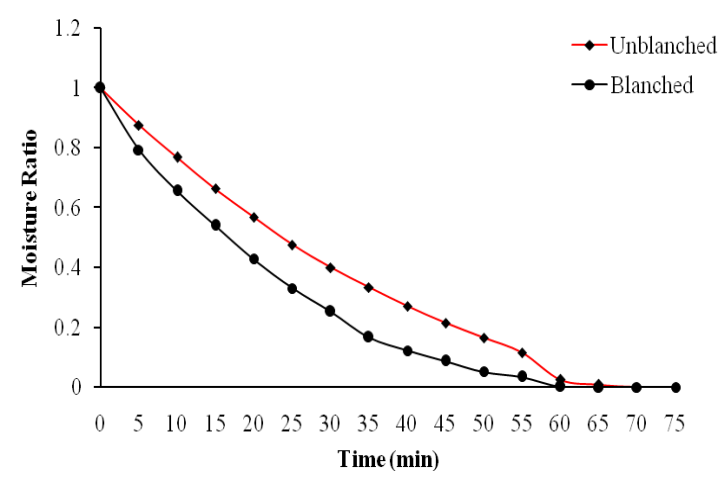

(a) Moisture ratio v/s Time curve

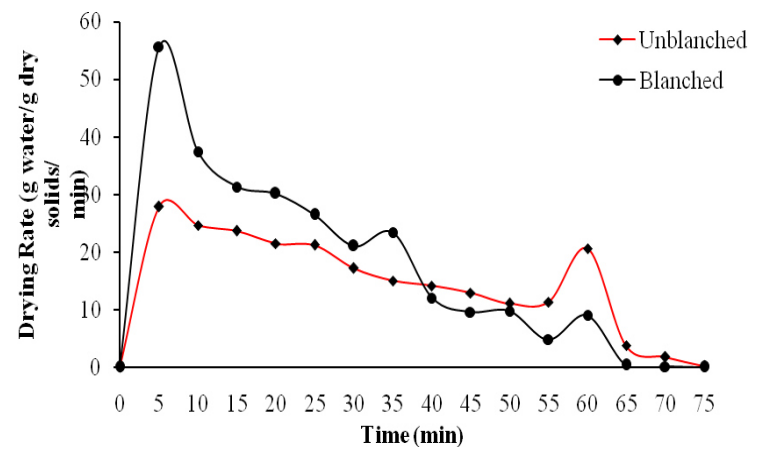

(b) Drying Rate v/s Time curve

Fig. 5: Microwave assisted hot air drying of bitter gourd slices with microwave power as $160 \mathrm{~W}$

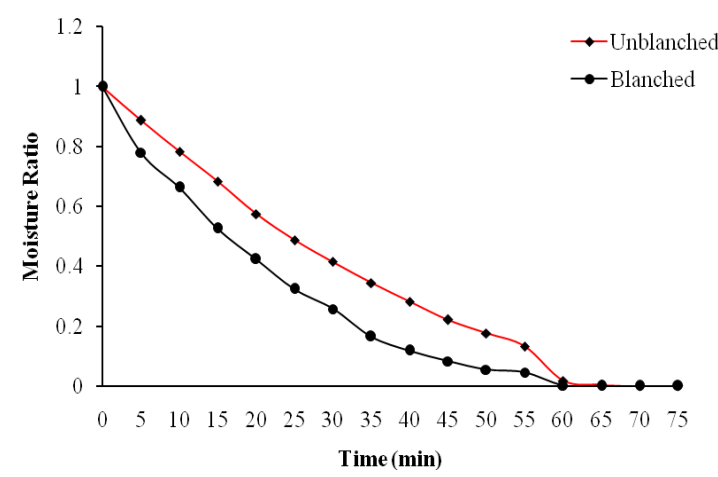

(a) Moisture ratio v/s Time curve

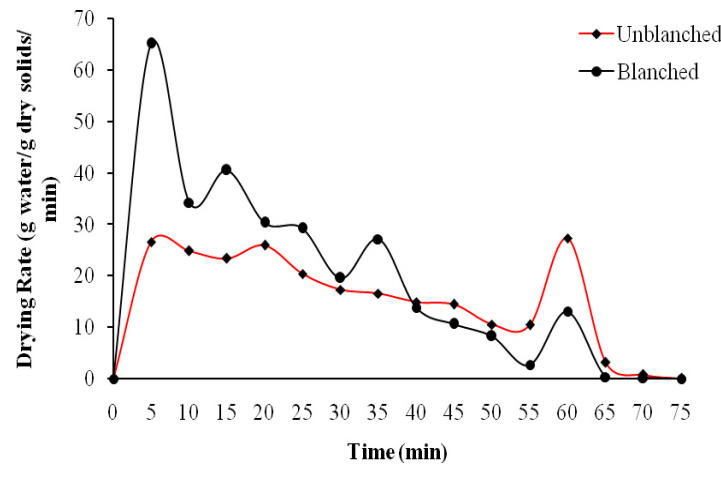

(b) Drying Rate v/s Time curve

Fig. 6: Microwave assisted hot air drying of bitter gourd slices with microwave power as $320 \mathrm{~W}$ 


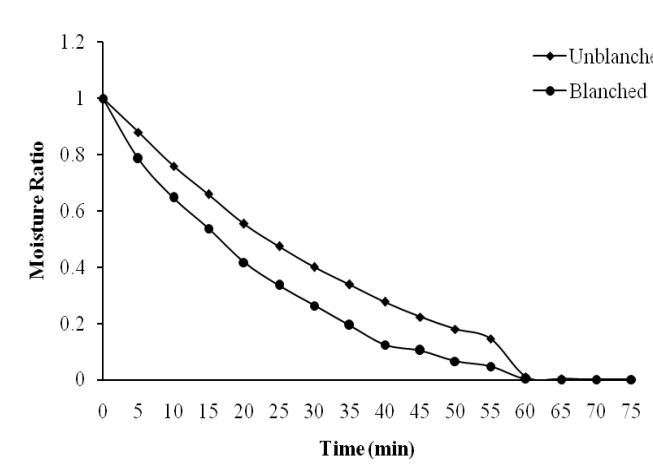

(a) Moisture ratio v/s Time curve

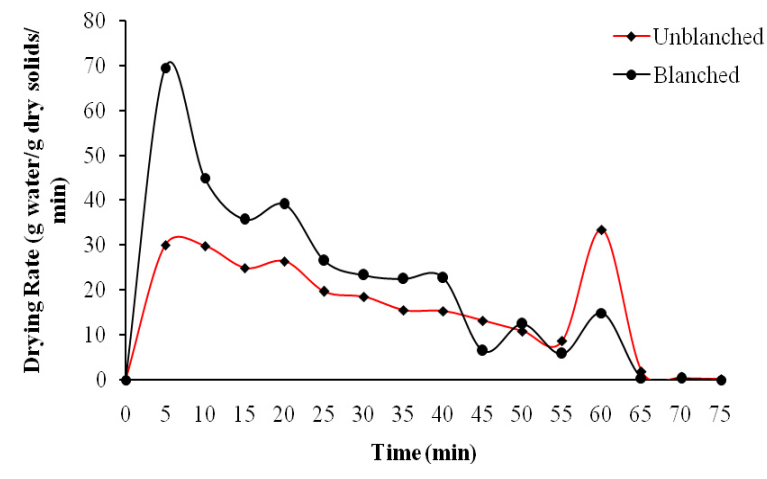

(b) Drying Rate v/s Time curve

Fig. 7: Microwave assisted hot air drying of bitter gourd slices with microwave power as $480 \mathrm{~W}$

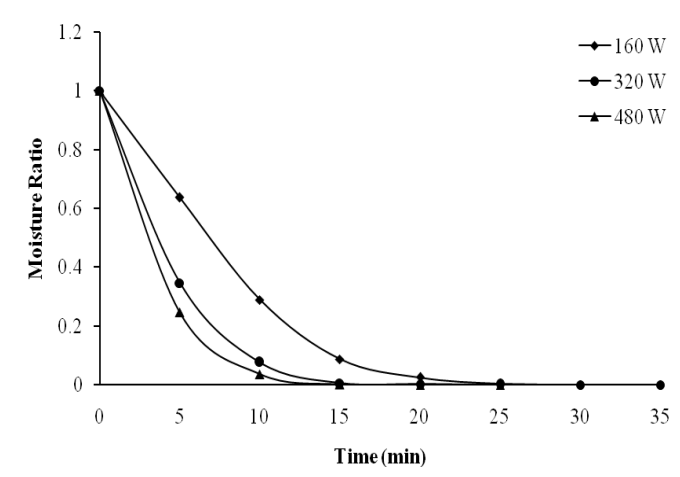

(a) Moisture ratio v/s Time curve

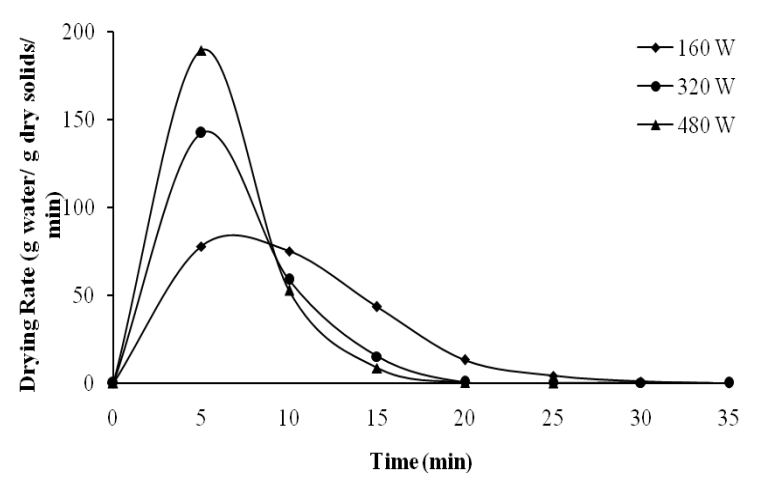

(b) Drying Rate v/s Time curve

Fig. 8: Drying of unblanched bitter gourd sample at different microwave powers

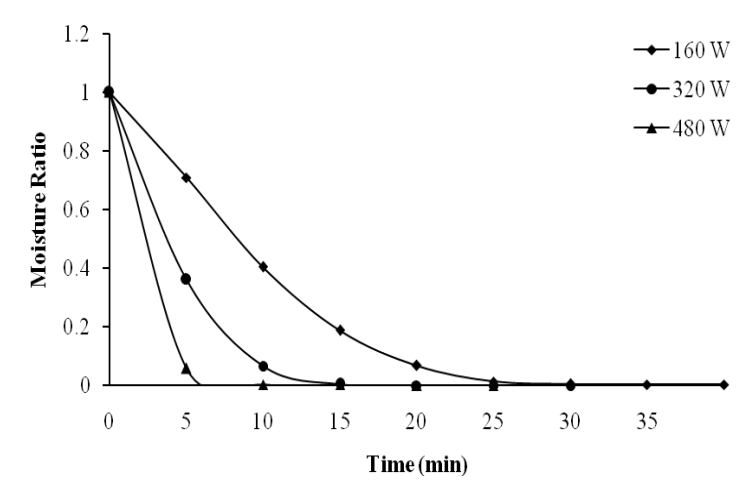

(a) Moisture ratio v/s Time curve

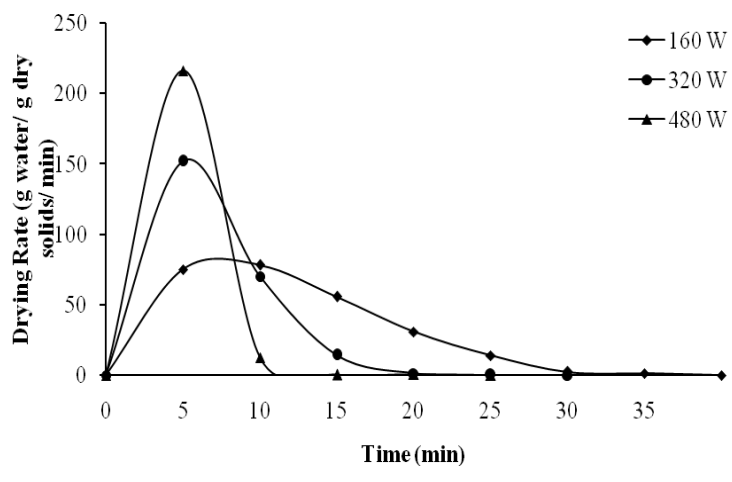

(b) Drying Rate v/s Time curve

Fig. 9: Drying of blanched bitter gourd sample at different microwave power 


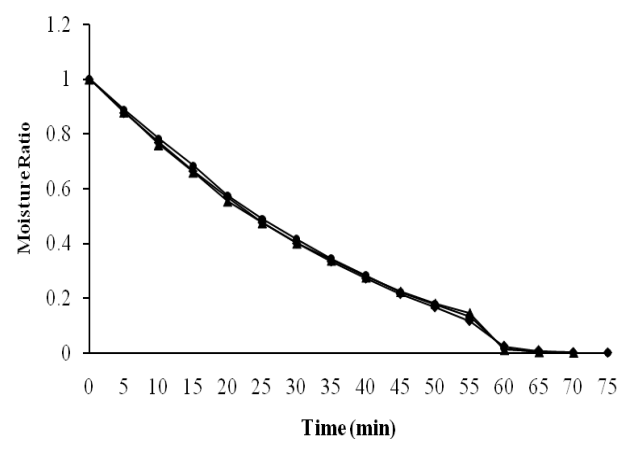

(a) Moisture ratio v/s Time curve

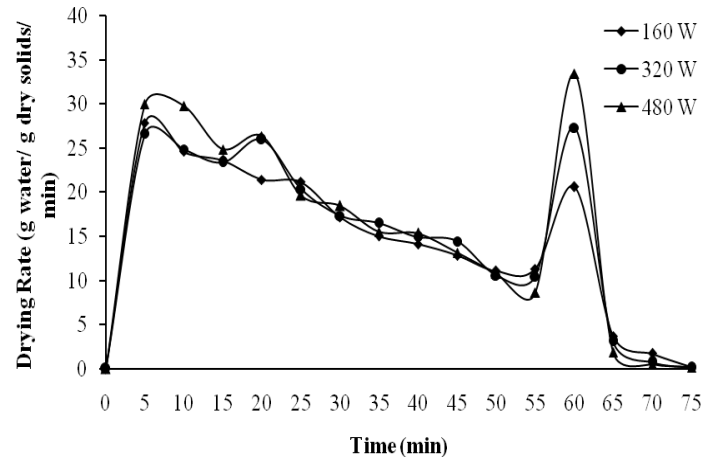

(b) Drying Rate v/s Time curve

Fig. 10: Drying of unblanched bitter gourd sample during microwave assisted hot air drying at different microwave powers

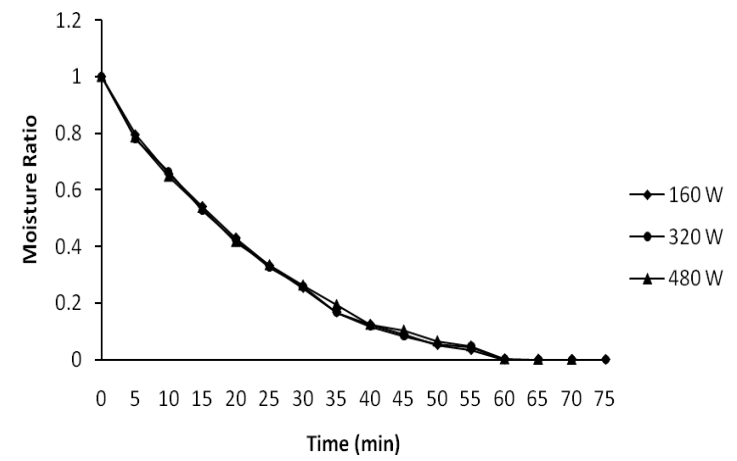

(a) Moisture ratio v/s Time curve

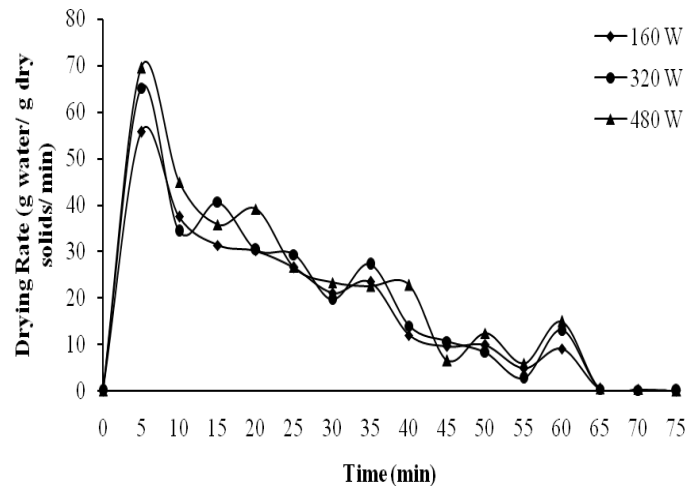

(b) Drying Rate v/s Time curve

Fig. 11: Drying of blanched bitter gourd sample during microwave assisted hot air drying at different microwave powers

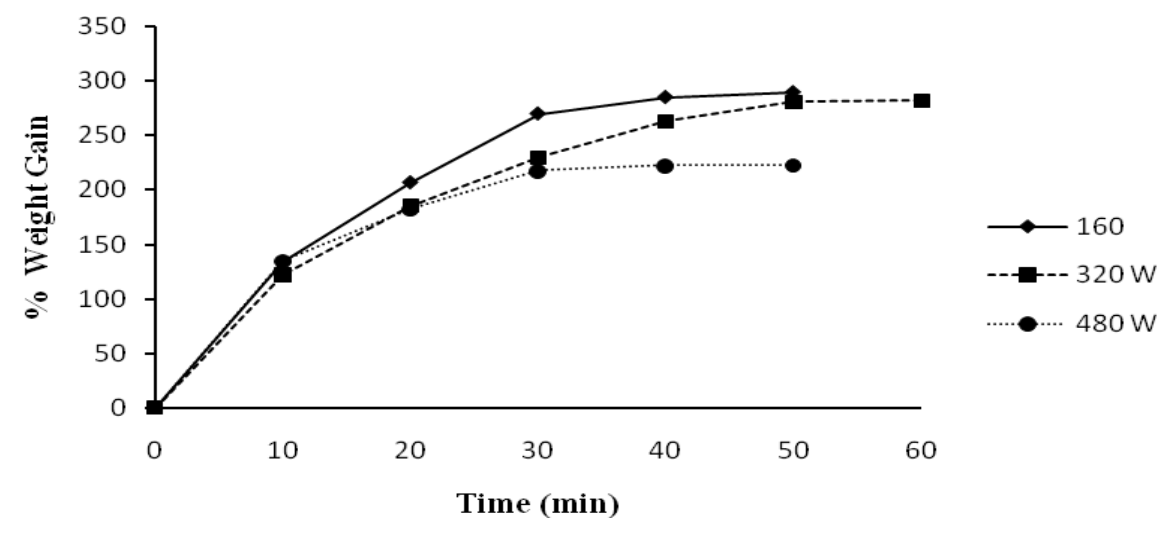

Fig. 12: Rehydration characteristics of unblanched sample at different microwave powers 


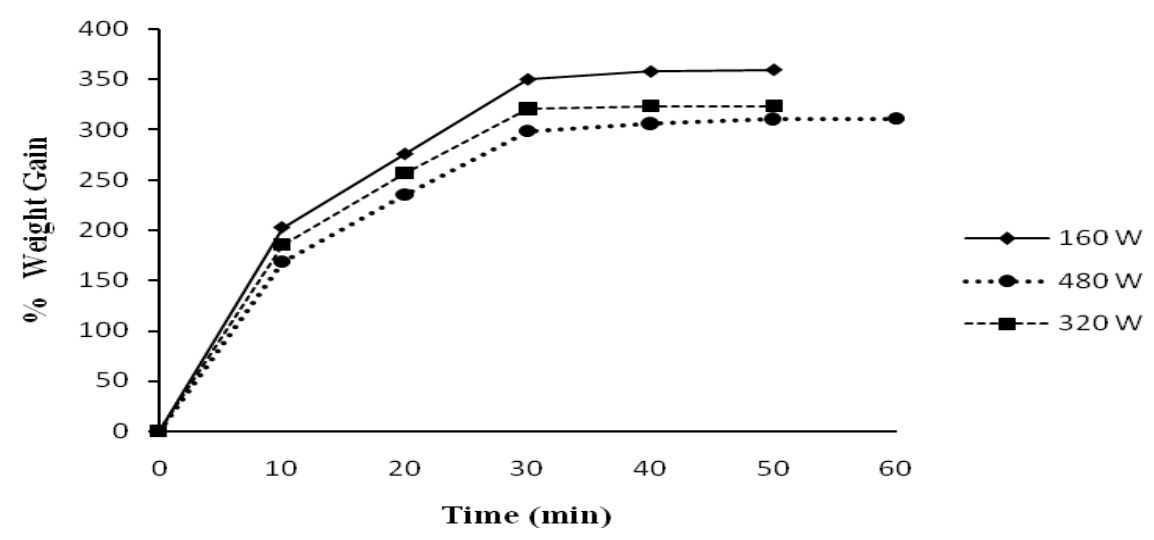

Fig. 13: Rehydration characteristics of blanched sample at different microwave powers

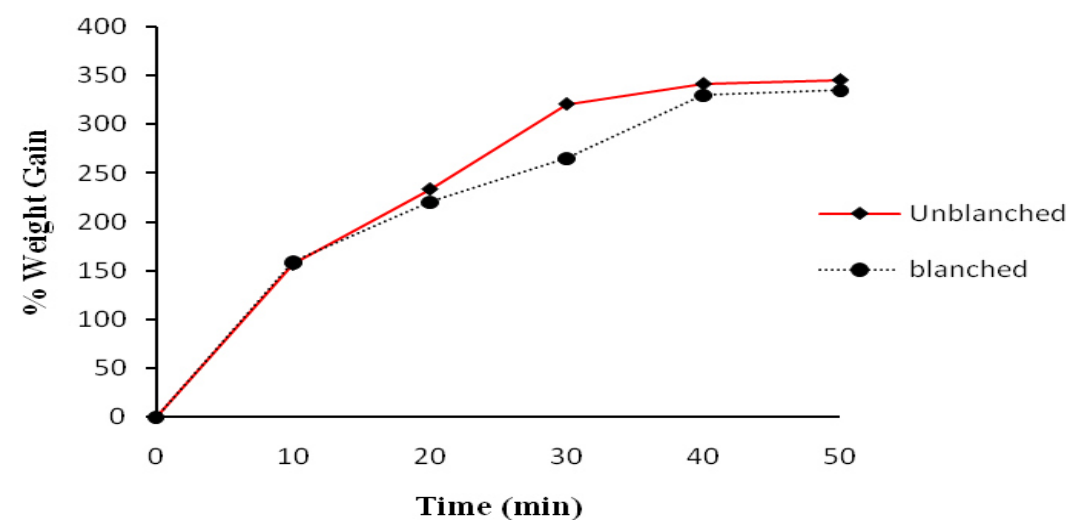

Fig. 14: Rehydration characteristics of sample dried in hot air dryer

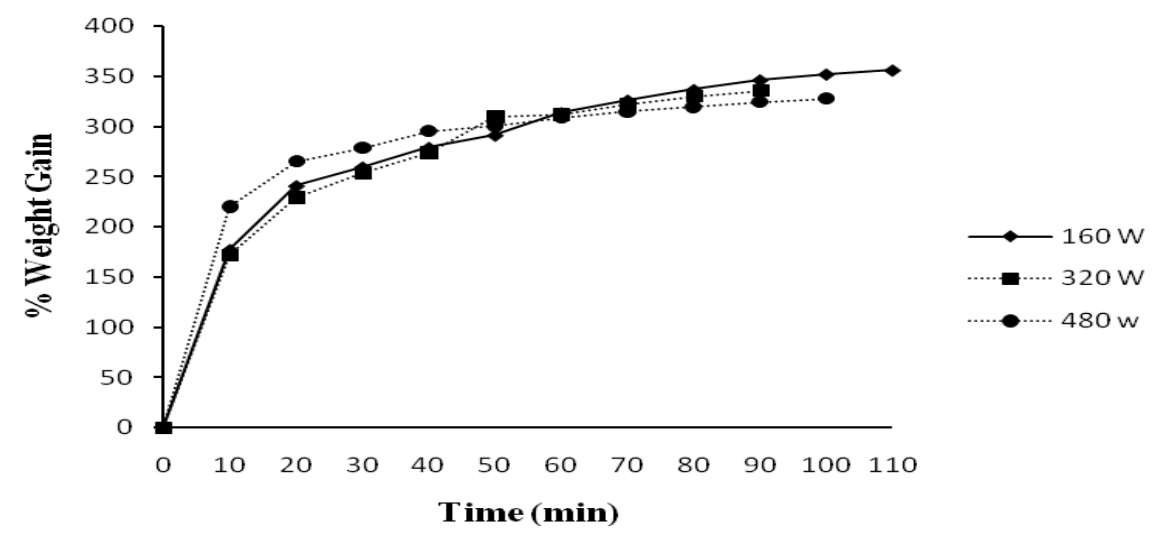

Fig. 15: Rehydration characteristics of unblanched sample in microwave assisted hot air drying 


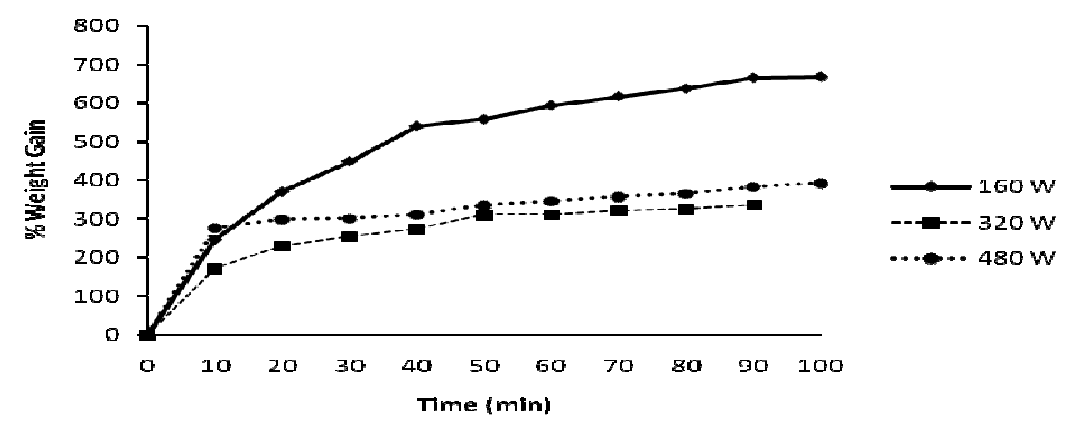

\section{Fig. 16: Rehydration characteristics of blanched sample in microwave assisted hot air drying}

hardening which does not allow further absorption of moisture from the sample. Similar results were obtained by Maskan (2001) during rehydration of kiwifruits. The blanched sample showed higher percentage of weight gain as compared to unblanched samples for all drying methods (Fig. 12, 13 and 14). Of all the experimental drying methods, the rehydration capacity of the sample dried in microwave assisted hot air drying method had the highest value (Fig. 15 and 16). This improved the rehydration capacity of bitter gourd. The rehydration capacity was more for blanched sample $(666.67 \%)$ as compared to unblanched sample (352.27\%) during microwave assisted hot air drying at $160 \mathrm{~W}$.

\section{Conclusion}

On the basis of experimental results and data, the study conclude that for all drying methods drying rate showed a fast increase at the beginning of the process and then subsequently reduced, showing two differential falling rate periods. In microwave drying, drying rate increased with an increase in the microwave power and also declined rapidly. Samples dried at higher power showed lower values of rehydration ratios.

The blanched samples showed better rehydration characteristics than the unblanched samples in all methods of drying. Although microwave assisted hot air drying took higher drying time (43\%) than microwave drying, it had better rehydration characteristics than the other two drying methods. Therefore, it can be used for preservation of high quality samples. Microwaveassisted hot air drying reduced the drying time by $45 \%$ as compare to hot air drying.

\section{References}

1. AOAC (1995). Official methods of analysis. Association of Official Analytical Chemists, Washington DC, USA.

2. Anonymous (2010). Database file: Bitter Melon; www.rainforest-database.come; accessed on 10-02-2012

3. Handerson, S.M., and Perry R.L. (1976). Agricultural process engineering. AVI Publishing, Westport CT.

4. Kaur, K. and Singh, A.K. (2014). Drying kinetics and quality characteristics of beetroot slices under hot air followed by microwave finish drying. African J Agric Res. 9(12): 1036-1044.

5. Kulkarni,A.S., Patil, H.B. and Mundada, C.G. (2005). Studies on effect of pretreatment on quality of dehydrated bitter gourd. Adit J Eng. 2(1): 31-33.

6. Maskan, M. (2000). Microwave/Air and microwave finish drying of banana. J Food Eng. 44(2): 71-78.

7. Maskan, M. (2001) Kinetics of color changes of kiwifruits during hot air and microwave drying. J Food Eng. 48: 169-175.

8. Maskan, M. (2001). Dying, shrinkage and Rehydration characteristics of kiwifruits during hot-air and microwave drying. J Food Eng., 48: 177-182.

9. Workneh, T.S. and Oke, M O. (2012). The influence of the combined microwave power and hot air ventilation on the drying kinetics and colour quality of tomato slices. African J Biotechnol. 11(87): 15353-15364. 